\title{
Serotonin-Induced Increases in Adult Cell Proliferation and Neurogenesis are Mediated Through Different and Common 5-HT Receptor Subtypes in the Dentate Gyrus and the Subventricular Zone
}

\author{
Mounira Banasr', Micheline Hery', Richard Printemps' and Annie Daszuta*,' \\ 'Cellular and Functional Neurobiology Unit, CNRS, Marseille, France
}

\begin{abstract}
Increase in serotonin (5-HT) transmission has profound antidepressant effects and has been associated with an increase in adult neurogenesis. The present study was aimed at screening the $5-\mathrm{HT}$ receptor subtypes involved in the regulation of cell proliferation in the subgranular layer (SGL) of the dentate gyrus (DG) and the subventricular zone (SVZ) and to determine the long-term changes in adult neurogenesis. The 5-HTIA, 5-HTIB, and 5-HT2 receptor subtypes were chosen for their implication in depression and their location in/ or next to these regions. Using systemic administration of various agonists and antagonists, we show that the activation of 5-HTIA heteroreceptors produces similar increases in the number of bromodeoxyuridine-labeled cells in the SGL and the SVZ (about 50\% over control), whereas 5-HT2A and 5-HT2C receptor subtypes are selectively involved in the regulation of cell proliferation in each of these regions. The activation of $5-\mathrm{HT} 2 \mathrm{C}$ receptors, largely expressed by the choroid plexus, produces a $56 \%$ increase in the SVZ, while blockade of 5-HT2A receptors produces a $63 \%$ decrease in the number of proliferating cells in the SGL. In addition to the influence of 5 HTIB autoreceptors on 5-HT terminals in the hippocampus and ventricles, 5-HTIB heteroreceptors also regulate cell proliferation in the SGL. These data indicate that multiple receptor subtypes mediate the potent, partly selective of each neurogenic zone, stimulatory action of 5-HT on adult brain cell proliferation. Furthermore, both acute and chronic administration of selective 5-HTI A and 5-HT2C receptor agonists produce consistent increases in the number of newly formed neurons in the DG and/or olfactory bulb, underscoring the beneficial effects of $5-\mathrm{HT}$ on adult neurogenesis.
\end{abstract}

Neuropsychopharmacology (2004) 29, 450-460, advance online publication, 15 December 2003; doi: I 0. I 038/sj.npp. I 300320

Keywords: adult neurogenesis; serotonin receptors; dentate gyrus; subventricular zone; olfactory bulb

\section{INTRODUCTION}

Accumulating evidence indicates that in the adult brain, neurogenesis from neural stem cells and progenitor cells continues in two regions: the subventricular zone (SVZ), which lines the lateral ventricles and gives rise to new interneurons that reach the olfactory bulb $(\mathrm{OB})$ via the rostral migratory stream (RMS), and the subgranular layer (SGL) of the dentate gyrus (DG), which generate new granule cells (Taupin and Gage, 2002). Extensive studies demonstrate that neurogenesis in the DG is modulated by both physiological stimuli (Kempermann et al, 1997; Gould

\footnotetext{
*Correspondence: Dr A Daszuta, LNCF, CNRS, Cellular and Functional Neurobiology Unit, 31 Ch. J. Aiguier, 13402 Marseille, France, Tel: 330 49I I 64 321, Fax: 330477 5083,

E-mail: daszuta@Incf.cnrs-mrs.fr

Received 02 October 2002; revised 14 August 2003; accepted 02 September 2003

Online publication: 3 September 2003 at http://www.acnp.org/ citations/Npp09030303366/default.pdf
}

et al, 1999) and pathophysiological conditions (Parent, 2002; Kokaia and Lindvall, 2003). In the normal mature brain, a large number of factors including exercise, environmental enrichment, aging, steroids, and neurotransmitters can regulate neurogenesis in the DG (Gage, 2000; Fuchs and Gould, 2000; Duman et al, 2001). Compared to the DG, much less studies are devoted to the SVZ, but recent data also demonstrate that selective environmental factors increase neurogenesis in the $\mathrm{OB}$ (Rochefort et al, 2002). Furthermore, hormonal, prolactin-stimulated neurogenesis during pregnancy contributes to olfactory discrimination (Shingo et al, 2003). These data indicate that defining the factors regulating adult neurogenesis helps to understand the functional role of newly formed cells. It can also be critical in the clinical perspective of brain repair.

Among molecular factors, only some trophic factors and serotonin (5-HT) can increase cell proliferation and neurogenesis both in the SVZ and SGL. We have previously demonstrated that changes in 5-HT transmission are associated with changes in adult cell proliferation, since 
Table I Effects of 5-HT Receptors Agonists and Antagonists on Cell Proliferation in the Two Neurogenic Zones of the Adult Brain

\begin{tabular}{|c|c|c|}
\hline Treatment & SGL & SVZ \\
\hline \multicolumn{3}{|l|}{ 5-HT IA } \\
\hline 8-OH-DPAT (agonist) & $\nearrow$ & $\nearrow$ \\
\hline PCPA+8-OH-DPAT & Reversal/PCPA & ND \\
\hline \multicolumn{3}{|l|}{$5-H T \mid B$} \\
\hline Sumatriptan (agonist) & - & $\forall$ \\
\hline GR 127935 (antagonist) & - & $\nearrow$ \\
\hline PCPA+Sumatriptan & Reversal/PCPA & No reversal/PCPA \\
\hline \multicolumn{3}{|l|}{$5-H T 2 A / 2 C$} \\
\hline DOI (antagonist) & - & $\pi$ \\
\hline Ketansenin (antagonist) & $\forall$ & - \\
\hline \multicolumn{3}{|l|}{$5-H T / 2 C$} \\
\hline RO $600 \mid 75$ (agonist) & - & $\nearrow$ \\
\hline SB 206553 (antagonist) & - & - \\
\hline
\end{tabular}

SGL: subgranular layer in the dentate gyrus; SVZ: subventricular zone; ND: not determined; - : no change.

significant decreases in the number of newborn cells in the SVZ and SGL are observed following either acute or chronic 5-HT depletion (Brezun and Daszuta, 1999, 2000a). Conversely, sprouting of serotonergic neurons in the DG reverses the lesion-induced changes, and overnormal levels of 5-HT produced by fetal raphe neurons grafted to the previously denervated hippocampus increase cell proliferation (Brezun and Daszuta, $2000 \mathrm{a}, \mathrm{b})$. From a more functional point of view, we also demonstrated that 5-HT mediates the estrogenstimulating effect on cell proliferation in the DG (Banasr et al, 2001). These data indicate that 5-HT can be viewed as an endogenous and local factor of stimulation of adult neurogenesis in the DG. However, its mechanism of action can be mediated by different receptor subtypes expressed near the proliferating cells by neuronal and glial populations (Barnes and Sharp, 1999). The aim of the present study was to determine which 5-HT receptor subtypes, among 5-HT1A, 5-HT1B, 5-HT2A, and 5-HT2C, are involved in the positive regulation of adult neurogenesis in the DG and SVZ of adult rats.

This study is also in line with recent hypotheses suggesting that upregulation of neurogenesis would oppose the action of stress or/and depression, raising the possibility that increased neurogenesis could contribute to the actions of antidepressants (Jacobs et al, 2000; Kempermann, 2002; Benninghoff et al, 2002b). Impaired serotonergic (5-HT) transmission has long been implicated in the pathogenesis of depression and use of selective 5-HT reuptake inhibitors (SSRI) has proved to be an effective treatment for depression (Middlemiss et al, 2002). For instance, fluoxetine ('prozac'), at increasing 5-HT concentrations, is classically used as an antidepressant drug and recent data show that the chronic administration of fluoxetine increases neuro- genesis in the adult rat hippocampus (Malberg et al, 2000; Manev et al, 2001b; Lee et al, 2001). A preliminary report suggests that increases in adult neurogenesis after fluoxetine administration require the activation of 5-HT1A receptors (Santarelli et al, 2003), which is consistent with a previous study showing that 5-HT1A receptor antagonists significantly decrease cell proliferation in the DG (Radley and Jacobs, 2002). Besides the implication of postsynaptic and presynaptic (autoreceptors) 5-HT1A receptors in depression, 5-HT2 receptors have also been involved in the effects of antidepressants (Middlemiss et al, 2002), as well as 5-HT1B receptors (Moret and Briley, 2000). Therefore, the present study was aimed at comparing the consequences of acute $v s$ chronic administration of selective agonists inducing increases in cell proliferation, on the phenotype of newly formed cells and the production of new neurons.

\section{MATERIALS AND METHODS}

\section{Animals}

Adult 8-week-old male Wistar rats (280-300 g; Iffa Credo, France) were group-housed ( 3 per cage) in a temperaturecontrolled room $\left(21^{\circ} \mathrm{C}\right)$ and maintained on a $12 \mathrm{~h}$ light/dark cycle with free access to food and water. This study was carried out in accordance with the French Agriculture and Forestry Ministry (decree 87848, license 01498). About 150 rats were used, and statistical analyses were performed on experimental groups each comprising five to seven rats.

\section{Acute Treatments and Cell Proliferation}

Acute treatments with agonists or antagonists of the different 5-HT receptor subtypes were followed by a single injection of 5'-bromodeoxyuridine (BrdU, Sigma, France, $200 \mathrm{mg} / \mathrm{kg}$, i.p.) $2 \mathrm{~h}$ before killing to examine the effect of these drugs specifically on cell proliferation.

Experiment 1. To determine whether 5-HT1A autoreceptors and/or heteroreceptors were involved in the serotonergic regulation of cell proliferation in the DG, rats were pretreated with an inhibitor of 5-HT synthesis parachlorophenylalanine (PCPA, Sigma, France; 300 and $100 \mathrm{mg} / \mathrm{kg}$, i.p. 48 and $24 \mathrm{~h}$ before the day of killing, respectively) and with the 5-HT1A agonist 8-hydroxy-2-(di$\mathrm{N}$-propylamino) tetralin (8-OH-DPAT) $(1 \mathrm{mg} / \mathrm{kg}$, i.p., Sigma, France) $2 \mathrm{~h} 30 \mathrm{~min}$ before killing. The respective control groups received either saline, PCPA, or 8-OH-DPAT alone following their respective timing. The implication of 5-HT1A receptors was also tested by injecting 8-OH-DPAT $4 \mathrm{~h}$ before killing in untreated rats.

Experiment 2. As for 5-HT1A receptors, we examined the consequences of sumatriptan, a 5-HT1B receptor agonist $(1 \mathrm{mg} / \mathrm{kg}$, i.p., GR 43175, kindly donated by Glaxo SmithKline, France) in PCPA-pretreated rats. Effects of sumatriptan alone were compared to those induced by GR 127935, a 5-HT1B/1D antagonist (3 mg/kg, i.p., Glaxo SmithKline, France). All groups were injected with agonist, antagonist, or saline (controls) $4 \mathrm{~h}$ before killing. 
Experiment 3. To determine the possible implication of 5HT2 receptors in the regulation of cell proliferation, we first used 2,5-dimethoxy-4-iodophenyl-2-aminopropane (DOI) (1 mg/kg, i.p., Sigma-RBI, France) and ketanserin ( $1 \mathrm{mg} /$ kg, i.p., Sigma-RBI, France) as 5-HT2A/2C agonist and antagonist, respectively. In order to discriminate between the two receptor subtypes, injections with either the selective 5-HT2C agonist RO $600175(2.5 \mathrm{mg} / \mathrm{kg}$, i.p., Hoffmann La Roche, Suisse) or antagonist SB 206553 $(1 \mathrm{mg} / \mathrm{kg}$, i.p., Sigma-RBI, France) were used. Again, rats were injected with saline, agonist, or antagonist $4 \mathrm{~h}$ before killing.

The doses of the serotonergic drugs used were determined based on the appropriate literature reports, specifically: 8-OH-DPAT, Owens et al (1990); sumatriptan, Mitsikostas et al (1996); GR 127935, Skingle et al (1996); DOI, Vaidya et al (1997); ketanserin, Semont et al (2000); RO 600175, Dekeyne et al (1999); SB 206553, Kennett et al (1996).

\section{Biochemistry}

The selectivity of the PCPA treatment was assessed on monoamine levels, since norepinephrine as 5-HT can regulate hippocampal cell proliferation (Kulkarni et al, 2002). Rats were killed by decapitation and the brains were quickly dissected out and kept on ice. The hippocampi were excised and determinations of 5-HT and norepinephrine tissue contents were performed using high-performance liquid chromatography along with an electrochemical detection method, as previously described (Compan et al, 1996). Changes in 5-HT levels were also measured in the striatum of treated and corresponding control rats $(n=5$ per group). Such a PCPA treatment induces a large decrease in hippocampal and striatal 5-HT levels (hippocampus: $0.03 \pm 0.01 v s 0.28 \pm 0.05$ in controls; means \pm SEM $\mu \mathrm{g} / \mathrm{g} \mathrm{w} /$ $\mathrm{w}$; striatum, $0.07 \pm 0.02$ vs $0.47 \pm 0.03$ in controls) without affecting hippocampal norepinephrine levels $(0.34 \pm 0.05 v s$ $0.38 \pm 0.08$ in controls; means \pm SEM $\mu \mathrm{g} / \mathrm{g}$ w/w).

\section{Acute $v s$ Chronic Treatments and Neurogenesis}

To determine the effects of acute activation of 5-HT1A or 5 -HT2C receptor subtypes on the production of new neurons, animals received a single injection of 8-OH-DPAT or RO 600175 at the same doses as previously mentioned and $\mathrm{BrdU}(75 \mathrm{mg} / \mathrm{kg}$, i.p.) was injected twice, $2 \mathrm{~h}$ and $3 \mathrm{~h}$ later. Rats were killed 4 weeks later. The chronic activation of these receptor subtypes was obtained by daily injection of 8-OH-DPAT or RO 600175 for 15 consecutive days. During the last 8 days of drug administration, $\mathrm{BrdU}(75 \mathrm{mg} / \mathrm{kg}$, i.p.) was injected twice daily 2 and $3 \mathrm{~h}$ after drugs. Animals were killed 4 weeks after the end of treatment. The respective control animals received the same protocol of saline and BrdU administrations.

\section{Tissue Preparation}

As previously described (Brezun and Daszuta, 2000a, b), the rats were deeply anesthetized with chloral hydrate $(400 \mathrm{mg} /$ $\mathrm{kg}$, i.p.) and transcardially perfused with $500 \mathrm{ml}$ of cold $4 \%$ paraformaldehyde in $0.1 \mathrm{M}$ phosphate buffer saline (PBS, $\mathrm{pH}$ 7.4). The brains were postfixed overnight at $4^{\circ} \mathrm{C}$ in the same solution, and soaked for 2 days in PBS containing 30\% sucrose for cryoprotection. For cell proliferation studies, frontal sections ( $40 \mu \mathrm{m}$ thick) were obtained using a cryostat-microtome from the dorsal hippocampus and the SVZ was taken at the level of the medial striatum, and collected free-floating in PBS before peroxidase immunostaining. In neurogenesis studies, $40 \mu \mathrm{m}$-thick frontal sections from the entire hippocampus (dorsal and ventral) were collected in PBS and sagittal sections $(20 \mu \mathrm{m}$ thick) of OB on polylysined slides. The quantifications in the DG, SVZ, and OB were performed after peroxidase immunostaining, while the phenotype was determined using confocal analyses on DG and OB.

\section{Peroxidase Immunostaining}

For BrdU immunostaining, the sections were first rinsed in $0.1 \mathrm{M}$ PBS, and incubated for $15 \mathrm{~min}$ in $1 \% \mathrm{H}_{2} \mathrm{O}_{2}$ and $10 \%$ fetal calf serum for $2 \mathrm{~h}$ as the blocking buffer. Then, the sections were incubated in $2 \mathrm{M} \mathrm{HCl}$ and $0.5 \%$ Triton X-100 in PBS $\left(30 \mathrm{~min}, 37^{\circ} \mathrm{C}\right)$ for DNA hydrolysis. The sections were rinsed in $0.1 \mathrm{M}$ sodium tetraborate buffer, $\mathrm{pH} 8.5$, before overnight $+24 \mathrm{~h}$ incubation with the primary antibody (monoclonal mouse IgG, $1: 200$, Dako, France) at $4{ }^{\circ} \mathrm{C}$, followed by incubation with the secondary antibody (polyclonal goat IgG, 1:200, Dako, France) for $2 \mathrm{~h}$ at room temperature, and revelation using $\mathrm{ABC}$ staining system (AbCys, France). Peroxidase activity was revealed by incubating sections with $0.025 \% 3,3^{\prime}$-diaminobenzidine (DAB) and $0.025 \%$ of $\mathrm{H}_{2} \mathrm{O}_{2}$ in $0.5 \mathrm{M}$ Tris buffered saline, $\mathrm{pH}$ 7.6. After several rinses, sections were dehydrated, mounted, and coverslipped in DEPEX medium.

\section{Immunofluorescence}

For confocal observations of 5-HT and BrdU labeling, the sections were first pretreated with $0.1 \mathrm{M}$ lysine and $1 \%$ $\mathrm{H}_{2} \mathrm{O}_{2}$, incubated for $30 \mathrm{~min}$ in $10 \%$ normal goat serum (NGS, Dako, France) in PBS containing 0.6\% Triton X-100, and then with rabbit polyclonal primary antisera against 5 -HT $\left(1: 200\right.$, Immunotech, France) for $72 \mathrm{~h}$ at $4{ }^{\circ} \mathrm{C}$, followed by incubation with TRITC-conjugated goat secondary antisera (1:200, Beckman Coulter, France) for $2 \mathrm{~h}$. After several rinses, the sections were pretreated and treated for fluorescence BrdU immunolabeling with the same primary and secondary antisera as mentioned above $(1: 100)$, followed by incubation with Oregon green-conjugated avidin for $2 \mathrm{~h}(1: 1000$, Interchim, France).

For BrdU/NeuN/GFAP labeling, the sections were pretreated with lysine, $\mathrm{H}_{2} \mathrm{O}_{2}$, and NGS, then incubated with mouse anti-NeuN (1:1000, Chemicon, France) and rabbit anti-GFAP $\left(1: 500\right.$, Dako, France) for $24 \mathrm{~h}$ at $4^{\circ} \mathrm{C}$. After rinses, the sections were exposed for $2 \mathrm{~h}$ to secondary fluorescent antibodies (Alexa 633-conjugated goat antimouse, Molecular Probe and FITC-conjugated goat antirabbit, Sigma, France) at room temperature. The sections were then treated as already mentioned and incubated with rat anti-BrdU for $24 \mathrm{~h}$ at $4{ }^{\circ} \mathrm{C}(1: 100$, AbCys, France $)$ followed by incubation with the secondary antibody (TRITC-conjugated donkey anti-rat antibody, $1: 100$, Jackson, France) for $2 \mathrm{~h}$ at room temperature. The sections were coverslipped in Mowiol mounting medium. 


\section{Stereological Counting Procedure}

A systemic random counting procedure, similar to the optical dissector (Gundersen et al, 1988), was used to determine the corresponding sample volume of the granule cell layer (GCL) of DG and OB, analyzed by tracing respective areas using a computer image analysis system (Biocom, France) connected by a camera to a Nikon Optiphot microscope. The areas were determined on cresyl violet sections adjacent to those taken for immunostaining. The section thickness $(40$ or $20 \mu \mathrm{m})$ was used for volume estimation. All the results were expressed as BrdUimmunoreactive nuclei per $\mathrm{mm}^{3}$, as previously described by Aberg et al (2000) and Rochefort et al (2002). An investigator blind to treatment history performed quantifications.

Hippocampus. In cell proliferation studies, BrdU cells were counted on adjacent sections in one-in-three series of every animal at the level of the dorsal hippocampus $(2.8-4.0 \mathrm{~mm}$ from interaural line, Pellegrino, 1979). A series of 10 sections per brain taken at $80 \mu \mathrm{m}$ intervals was used to count BrdU-labeled cells in the inner rim of GCL, SGL, defined as a two-cell bodies-wide zone of the hilus along the base of the GCL. For neurogenesis studies, the number of BrdU-labeled cells in the SGL and GCL were quantified on a series of every 10th section at $400 \mu \mathrm{m}$ intervals (10 sections by brain) spanning the entire hippocampus. As BrdUlabeled cells are rare in the DG, no counting frame was used and their number was then reported to the volume $\left(\mathrm{mm}^{3}\right.$ of GCL). To assess possible cell death after long-term treatments, pyknotic cells were counted on cresyl violet sections in the SGL and GCL.

Subventricular zone. Every third section from the junction of the corpus callosum to the lateral extension of the commissural anterior was used for analysis. BdrUlabeled cells were counted in the walls of the lateral ventricles on six sections of SVZ $(120 \mu \mathrm{m}$ intervals) per brain taken between 7.8 and $8.8 \mathrm{~mm}$ from the interaural line (Pellegrino, 1979). The total number of BrdUlabeled cells was counted and expressed per SVZ and per section.

Olfactory bulb. We quantified the number of BrdU cells in the GCL on a series of every third sagittal section $(40 \mu \mathrm{m}$ intervals) of the right $\mathrm{OB}$, resulting in five to six sections per animal. A counting frame of $325 \times 325 \mu \mathrm{m}^{2}$ was used to count BrdU-labeled cells under exclusion of cells intersected in the uppermost focal plane and the lateral boundaries of the frame. The number of BrdU-positive cells was expressed per $\mathrm{mm}^{3}$ of GCL.

Cell differentiation. To determine the percentage of neuronal or glial differentiation of newborn cells for each neurogenic region, 50 BrdU-positive cells were randomly selected and each one was analyzed in its entire $\mathrm{z}$-axis with $0.5 \mu \mathrm{m}$ steps in order to exclude false double labeling. The quantifications were performed using a confocal microscope (Olympus confocal laser scanning microscope, Olympus, France) equipped with a $\times 40$ oil objective.

\section{Statistical Analysis}

The data are expressed as mean number of cells per $\mathrm{mm}^{3} \pm \mathrm{SEM}$, except for SVZ analyses. All statistical analyses were performed with the Stat view-computer package. A $t$-test was performed when comparing two groups and oneway analysis of variance (ANOVA) was used for comparing multiple groups. Post hoc comparisons were made with a Newman-Keul's test. Significance was set at $p<0.05$ or 0.01 .

\section{RESULTS}

\section{Cell Proliferation}

The proliferation of progenitor cells was determined by immunohistochemical detection of BrdU within the nuclei of dividing cells. Acute-treated and corresponding control rats were killed $2 \mathrm{~h}$ after a single BrdU injection.

Dentate gyrus. Immunostaining for 5-HT fibers is detected in the hilus and the molecular layer of the DG, mainly avoiding the granular layer, and 5-HT fibers are also frequently observed lining the SGL next to the BrdU-labeled cells (Figure 1a). In this region, the BrdUlabeled cells that are located in the subgranular zone at the border between the GCL and the hilus have irregularly shaped nuclei and diffuse patterns of BrdU staining (Figure 3a).

5-HT1A receptors: As shown in Figure 2a, the activation of 5-HT1A receptors for $4 \mathrm{~h}$ with 8-OH-DPAT induces a significant increase ( $51 \%$ over control) in the number of BrdU-positive cells (8-OH-DPAT: $1242 \pm 152$ vs control: $822 \pm 95$ as mean number of BrdU-positive cells $/ \mathrm{mm}^{3}$ of $\mathrm{GCL} \pm \mathrm{SEM}$ ) that frequently form clusters (Figure $3 \mathrm{~b}$ ). A shorter duration of activation of 5-HT1A receptors $(2 \mathrm{~h}$ $30 \mathrm{~min}$ ) produces no change in the level of cell proliferation in control rats, but abolishes the decrease in the number of BrdU-positive cells induced by inhibiting 5-HT synthesis using PCPA treatment (PCPA +8 -OH-DPAT: $799 \pm 87 v s$ PCPA: $327 \pm 142$ ).

5-HT1B receptors: As regards the 5-HT1B receptors (Figure 2b), neither the agonist, sumatriptan, nor antagonist, GR 127935, produces significant changes in the number of BrdU-positive cells in the SGL of DG (control: $937 \pm 25$; sumatriptan: $845 \pm 37$; GR 127935: $920 \pm 132$ ). However, the administration of sumatriptan in PCPA-pretreated rats restores a normal level of cell proliferation (PCPA + sumatriptan: $995 \pm 155$ vs PCPA: $417 \pm 90)$.

5-HT2 receptors: No significant change in cell proliferation in the SGL is observed following DOI administration, the 5-HT2A/2C agonist (Figure 2c), but ketanserine, a 5HT2A/2C antagonist, produces a large decrease (63\%) in the number of BrdU-labeled cells (control: 1222 \pm 72 ; DOI: $1290 \pm 127$; ketanserin: $457 \pm 180$ ) (Figure 2c). Furthermore, selective activation or inhibition of the 5-HT2C receptors by RO 600175 and SB 206553, respectively, has no effect on cell proliferation in this region (control: $972 \pm 70$; RO 600175: 1145 \pm 70 ; SB 206553: $1022 \pm 155$ ). 

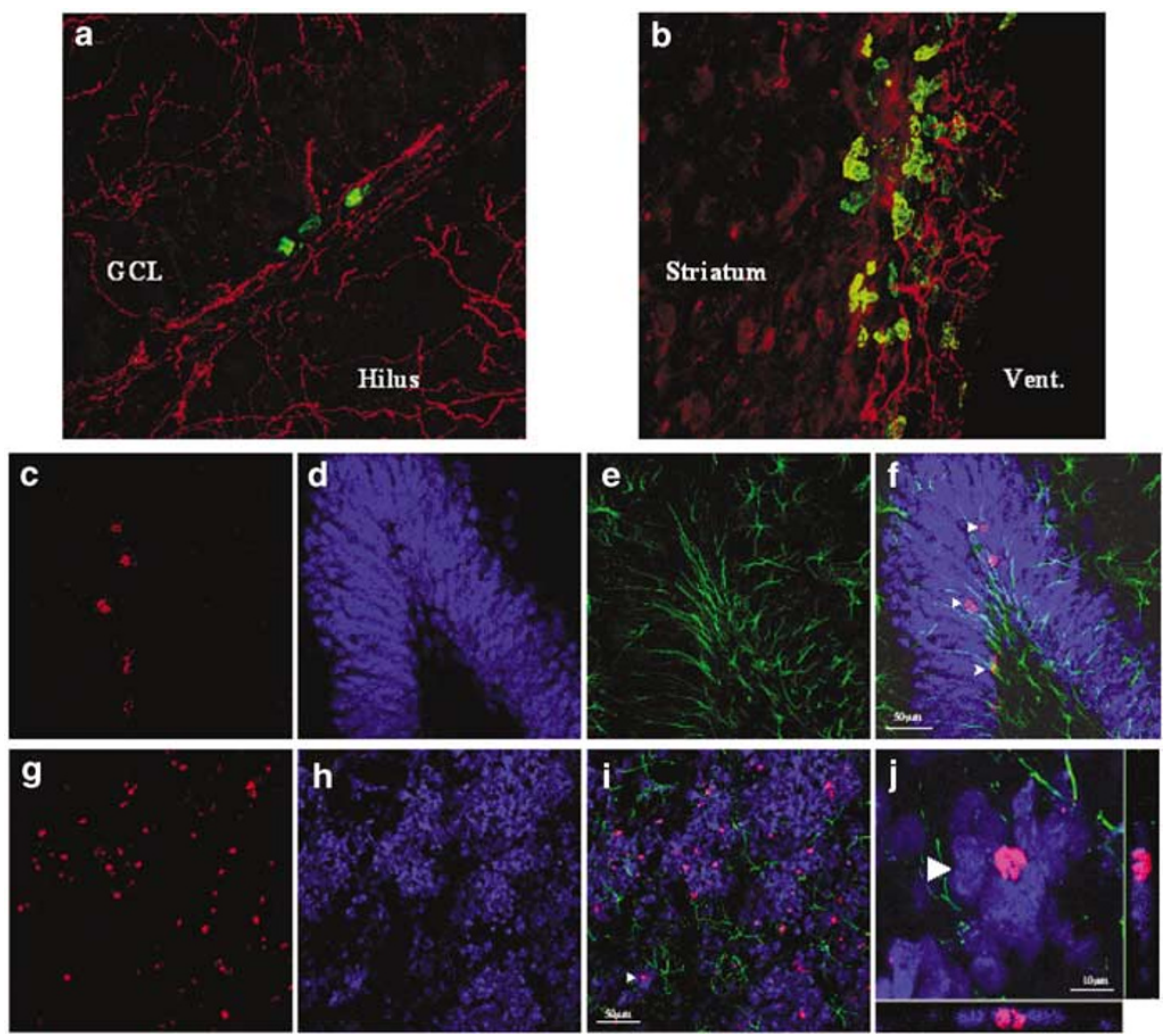

Figure I Illustrations in the DG of double immunostaining for 5-HT and BrdU (a), triple immunostaining for BrdU, NeuN, and GFAP (c- $f$ ) and of similar double (b) and triple immunostaining in the subventricular zone (b) and $\mathrm{OB}(\mathrm{g}-\mathrm{j})$ obtained by using confocal microscopy. A dense 5-HT axonal plexus (red) is detected in the molecular layer of the DG and in the hilus near the SGL containing BrdU-labeled cells (green), while very few serotonergic axons ramify into the GCL (a). At the striatal level, 5-HT-containing axons are observed in the walls of the lateral ventricles intermingled with BrdU-labeled nuclei (b) Simultaneous detection in the DG of immunofluorescent labels for BrdU (red, c), neuron-specific marker NeuN (blue, d), and glial cells with GFAP (green, e), and a merge of these signals ( $f$ showing newly generated cells having incorporated BrdU and labeled with NeuN (purple, arrow head) or with GFAP (yellow, arrow). Similar illustrations for the OB show on the same focal plane, BrdU (g) and NeuN (h) coexpressed in (i). The specificity of BrdU-NeuN coexpression in three dimensions is demonstrated in (j) on a higher magnification of the arrow-pointed cell in (i).

Subventricular zone. A dense plexus of 5-HT immunoreactive fibers is observed in the walls of the lateral ventricles intermingled with BrdU-labeled cells (Figure 1b).

5-HT1A receptors: As shown in Figure 4a, cell proliferation in the SVZ is largely increased (53\% over control) $4 \mathrm{~h}$ after administration of 8-OH-DPAT (control: $310 \pm 5$ vs 8OH-DPAT: $475 \pm 17$ as mean number of BrdU-labeled cells/ section \pm SEM).

5-HT1B receptors: The activation of 5-HT1B receptors by sumatriptan produces a $26 \%$ decrease in the number of BrdU-labeled cells in the SVZ (Figure 4b), while GR 127935 has the opposite effect (control: $300 \pm 15$; sumatriptan: $221 \pm 18 ;$ GR 127935: $367 \pm 8$ ). Rats treated with PCPA exhibit 36\% decreases in the number of BrdU-positive cells and such a pretreatment combined with sumatriptan produces similar effect as PCPA alone (PCPA: 194 \pm 11 ; PCPA + sumatriptan: $196 \pm 8$ ).

5-HT2 receptors: DOI administration produces a $24 \%$ increase in cell proliferation (Figure 4c), while ketanserin has no effect on the mean number of BrdU-positive cells in the SVZ (control: $340 \pm 17$; DOI: $420 \pm 4$; ketanserin: $335 \pm 39$; Figure $3 \mathrm{~d}$ and e). The increase in cell proliferation is further augmented $(+56 \%)$ after RO 600175 administration (Figure 3f), and no change is observed following $\mathrm{SB}$ 206553 (control: $320 \pm 24$; RO 600175: $501 \pm 31$; SB 206553: $286 \pm 22$ ).

Results are summarized in Table 1.

\section{Neurogenesis}

To determine the consequences of increases in cell proliferation induced by injections of 8-OH-DPAT or RO 600175 , the survival and fate of new cells in the GCL and OB were examined 4 weeks after either acute or chronic (15 days) treatments with 5-HT receptor agonists. In these longterm experiments, BrdU-positive cells were quantified and their phenotype were determined by using the neuronal marker, NeuN (Figure 1d and h), and the astroglial marker, GFAP (Figure 1e). Furthermore, multiple injections of BrdU were used: two for acute or more for chronic treatments with 5-HT receptor agonists.

\section{Dentate gyrus.}

5-HT1A receptors: In the DG (Figure 5a and b), the number of BrdU cells is significantly increased after either acute or chronic 8-OH-DPAT treatments $(+25,+29 \%$ respectively), compared with corresponding controls (acute 

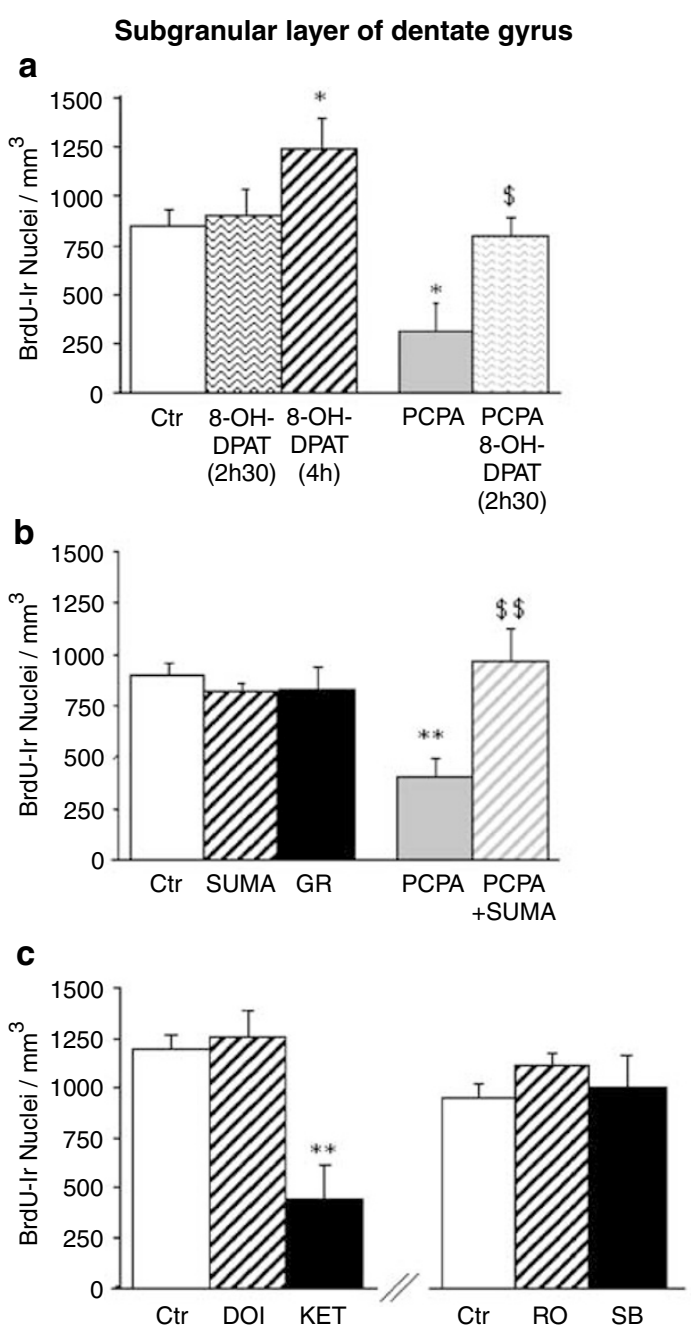

Figure 2 Histograms showing the effects of serotonergic agonists and antagonists on the numbers of BrdU-labeled cells in the SGL of the DG. (a) A prolonged activation of $5-\mathrm{HTIA}$ receptors (4 vs $2 \mathrm{~h} 30 \mathrm{~min}$ ) by $8-\mathrm{OH}-$ DPAT is necessary to stimulate cell proliferation in untreated rats. Furthermore, 8-OH-DPAT reverses the decrease in the number of BrdU-labeled cells observed in serotonergic-depleted rats (PCPA). (b) Treatments with the 5-HTIB/ID receptor agonist, sumatriptan (SUMA), or antagonist GR 127935 (GR) do not affect cell proliferation, but sumatriptan administration reverses the decrease induced by PCPA. (c) Administration of $\mathrm{DOI}$, the $5-\mathrm{HT} 2 \mathrm{~A} / 2 \mathrm{C}$ receptor agonist, produces no change in cell proliferation, whereas the antagonist, ketanserin (KET), induces a large decrease in the number of BrdU-labeled cells. Selective activation or blockade of 5-HT2C receptors by RO 600175 (RO) and SB 206553 (SB), respectively, has no effect on cell proliferation in the SGL. Data are presented as numbers of BrdU-labeled cells per $\mathrm{mm}^{3}$ of $\mathrm{GCL}$ (mean$s \pm S E M$ ) from five or six rats per group. $* p<0.05, * * p<0.0$ I compared to controls (Ctr); ${ }^{\$} p<0.05,{ }^{\$ \$} p<0.01$ compared to PCPA-treated rats.

8-OH-DPAT: $3233 \pm 255$ vs control $2576 \pm 74$ as the mean number of BrdU-positive cells $/ \mathrm{mm}^{3}$ of GCL \pm SEM; chronic 8-OH-DPAT: $18419 \pm 981$ vs control $14244 \pm 732$ ). As illustrated in Figure 1c-f, the majority of BrdU-positive cells are neurons (about 70\%) and not astrocytes (about 10\%), and no significant differences are detected when comparing control and treated rats (Figure $5 \mathrm{a}$ and $\mathrm{b}$ ). No change is observed in the total volume of GCL after such a treatment, as in the number of pyknotic cells (control: 21.1 \pm 4.9 ,
8-OH-DPAT: $30.1 \pm 4.1$ as the mean number of pyknotic cells $/ \mathrm{mm}^{3}$ of GCL \pm SEM), which are characterized by a lack of nuclear membrane, condensed, darkly stained, spherical chromatin, and pale cytoplasm (not illustrated).

5-HT2C receptors: Although no change in cell proliferation is observed after a single injection of the 5-HT2C receptor agonist, RO 600175, we examined the hypothesis that some modification could occur following chronic administration of the drug. As previously described for cell proliferation, no effect on cell neurogenesis in the DG is observed after chronic RO 600175 treatment (control: $14244 \pm 732$ vs RO 600175: $12543 \pm 1142$, as the mean number of BrdU-positive cells $/ \mathrm{mm}^{3}$ of GCL \pm SEM).

Olfactory bulb. Very few BrdU-positive cells were seen in the RMS 4 weeks after multiple BrdU injections, but a large number of BrdU-labeled cells were found scattered throughout the GCL in OB (Figure $1 \mathrm{~g}-\mathrm{i}$ ).

5-HT1A receptors: A significant increase $(48 \%)$ in the number of BrdU-positive cells is observed several weeks after a single injection of 8-OH-DPAT (Figure 5c) compared with corresponding controls (8-OH-DPAT: 2552 \pm 110 , control: $1722 \pm 300$ as the mean number of BrdU-positive cells $/ \mathrm{mm}^{3}$ of GCL of $\mathrm{OB} \pm \mathrm{SEM}$ ). A similar increase is detected following chronic treatment (Figure 5d) with this 5-HT receptor agonist (8-OH-DPAT: $21198 \pm 1510$, control: $14824 \pm 2010)$.

5-HT2C receptors: Single administration of the 5-HT2C receptor agonist, RO 600175, also produces a significant and persistent increase in the number of BrdU-positive cells/ $\mathrm{mm}^{3}$ of GCL of OB $(2557 \pm 30$ vs control: $1722 \pm 300$, mean \pm SEM; Figure 5c). Similar changes are observed following chronic treatment (RO 600175: $21953 \pm 2730 v s$ control: $14824 \pm 2010$; Figure 5d).

Neither the duration of treatment nor the receptor subtype affects the ratio of $\mathrm{BrdU}+/ \mathrm{NeuN}+$ and $\mathrm{BrdU}+I$ $\mathrm{GFAP}+v s$ total BrdU + cells. Most of the BrdU-labeled cells are NeuN positive $(>90 \%)$ and very few, $1-2 \%$, GFAP positive (Figure 1j).

\section{DISCUSSION}

The present findings show that 5-HT stimulates cell proliferation in the SGL and SVZ throughout several serotonergic receptor subtypes. The activation of 5-HT1A heteroreceptors produces similar increases in both regions, but 5-HT2A and 5-HT2C receptors are selectively involved in the regulation of cell proliferation in the SGL of DG and SVZ, respectively. Whereas 5-HT1B autoreceptors regulate 5-HT action in the SVZ and DG, 5-HT1B heteroreceptors are involved in the regulation of cell proliferation in the SGL. Finally, both acute and chronic administrations of 5-HT1A and 5-HT2C receptor agonists can produce significant increases in the number of newly formed neurons in the $D G$ and/or $O B$, without affecting the differentiation into a neuronal $v s$ glial phenotype. 

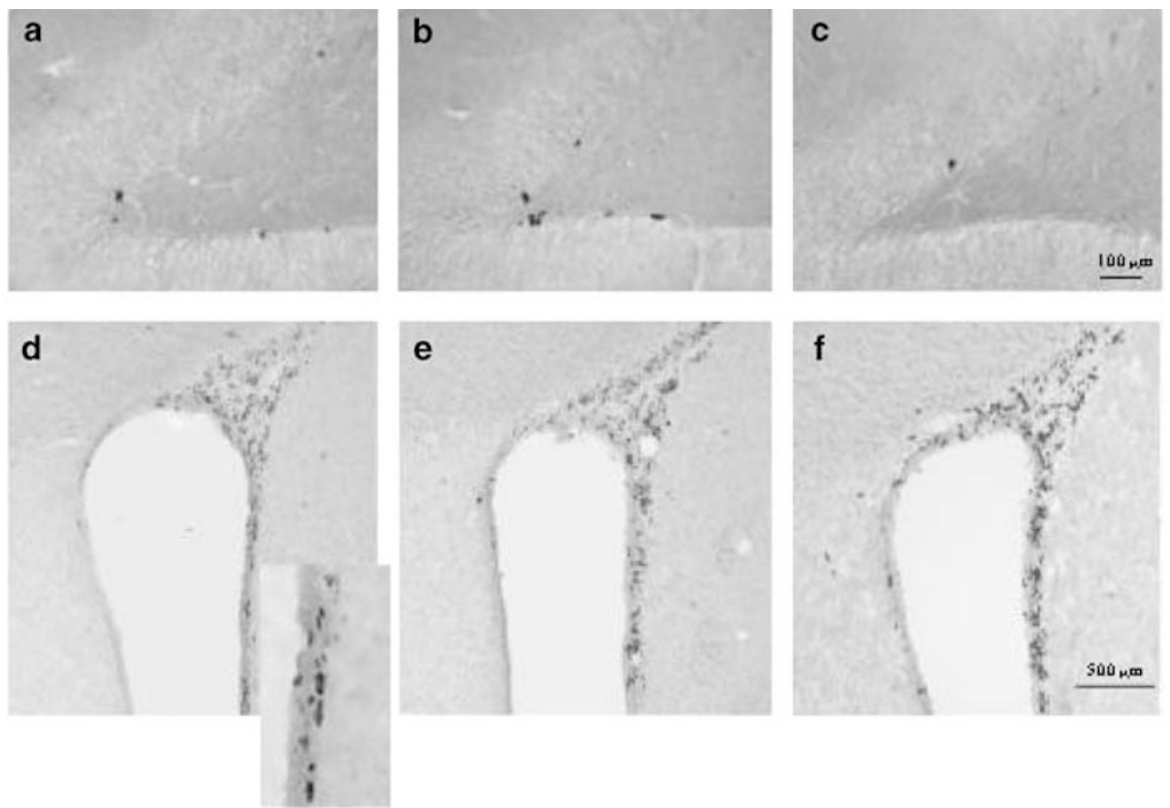

Figure 3 Photomicrographs of BrdU-labeled cells in the DG and the subventricular zone obtained by using peroxidase immunostaining. As compared with control (a), an increase in the number of dividing cells is observed in the SGL of rats treated with 5-HTIA receptor agonist, 8-OH-DPAT (b), whereas administration of the 5-HT2A/2C receptor antagonist, ketanserin, induces a decrease in the number of BrdU-labeled cells (c), compared to control (a). In the SVZ, the increase in cell proliferation observed following administration of the 5-HT2A/2C receptor agonist DOI (e) is larger in rats treated with the selective 5-HT2C receptor agonist RO 600175 (f), as compared to control (d).

\section{Regulation of Cell Proliferation and Neurogenesis in the DG}

The prolonged activation of 5-HT1A receptors by 8-OHDPAT produces a significant increase in cell proliferation in the DG. These results are consistent with the decreases in cell proliferation observed in the SGL following acute administration of various types of 5-HT1A receptor antagonists (Radley and Jacobs, 2002). The balance between the activation of 5-HT1A autoreceptors and heteroreceptors might have been an explanation for the primary lack of effect of 8-OH-DPAT when injected $30 \mathrm{~min}$ before BrdU, but the activation of 5-HT1A receptors in PCPA-pretreated rats reverses the PCPA-induced decrease in the number of BrdU nuclei, indicating that 5-HT1A heteroreceptors are implicated in the serotonergic regulation of cell proliferation, in the DG. Although it is not known whether such increases in the number of BrdU nuclei reflect changes in the size of the population of proliferating cells and/or changes in the rate of progression through the cell cycle, the second hypothesis may be supported by the presence of clusters observed in 8-OH-DPAT-treated rats.

Our previous data showing the potent stimulation of cell proliferation in the DG following intrahippocampal raphe grafts indicate that the action of 5-HT should be local (Brezun and Daszuta, 2000b). Indeed, 5-HT1A and not 5HT7 receptors, which are both activated by $8-\mathrm{OH}-\mathrm{DPAT}$, might be expressed by neural stem cells, as recently described on neurospheres derived from adult hippocampus (Benninghoff et al, 2002a). Additionally, the activation of 5-HT1A receptors expressed by astrocytes (WhitakerAzmitia et al, 1993), some of them behaving as transient precursors (Alvarez-Buylla et al, 2002), may lead to a potent augmentation of newly formed cells in the DG. The 5-HT1A receptors on astrocytes can also help to control the secretion of neurotrophic factors implicated in the regulation of cell proliferation, such as IGF-I (Aberg et al, 2000) or S100b (Manev et al, 2001a). Furthermore, 5-HT1A expressed by the mature granule cells ( $\operatorname{Riad}$ et al, 2000) can participate in the regulation of cell proliferation in this region. Indeed, there is a negative correlation between the rate of neurogenesis and the level of activity of dentate mature granule cells (Cameron et al, 1995). It has been well demonstrated that the glutamatergic transmission inhibits cell proliferation in the DG via NMDA receptors (Cameron et al, 1995; Gould et al, 1997; Nacher et al, 2001), which are expressed by granule cells, as 5-HT1A receptors. Hyperpolarization of these cells following activation of postsynaptic 5-HT1A receptors (Piguet and Galvan, 1994) would counterbalance this negative control. Finally, long-term analyses of neurogenesis following acute or chronic activation of 5-HT1A receptors indicate that the increases in cell proliferation are not transient and are followed by a significant augmentation in the number of newly formed neurons in DG.

As for 5-HT1A, interpretations regarding 5-HT1B receptors have to take the part of auto- $v s$ hetero-receptors in the regulation of cell proliferation. While 5-HT1B autoreceptors are implicated both in the SVZ and DG, 5-HT1B heteroreceptors appear to be selectively implicated in the DG. Following the administration of 5-HT1B receptor agonist, the increases in cell proliferation observed in the DG of PCPA-pretreated rats, that is, when 5-HT1B autoreceptors are not stimulated, indicate that the inhibition of glutamate release by presynaptic 5-HT1B heteroreceptors (Maura et al, 1998) may contribute to these changes. These data are consistent with the view previously mentioned that interactions between the glutamatergic and serotonergic 
Subventricular zone

a
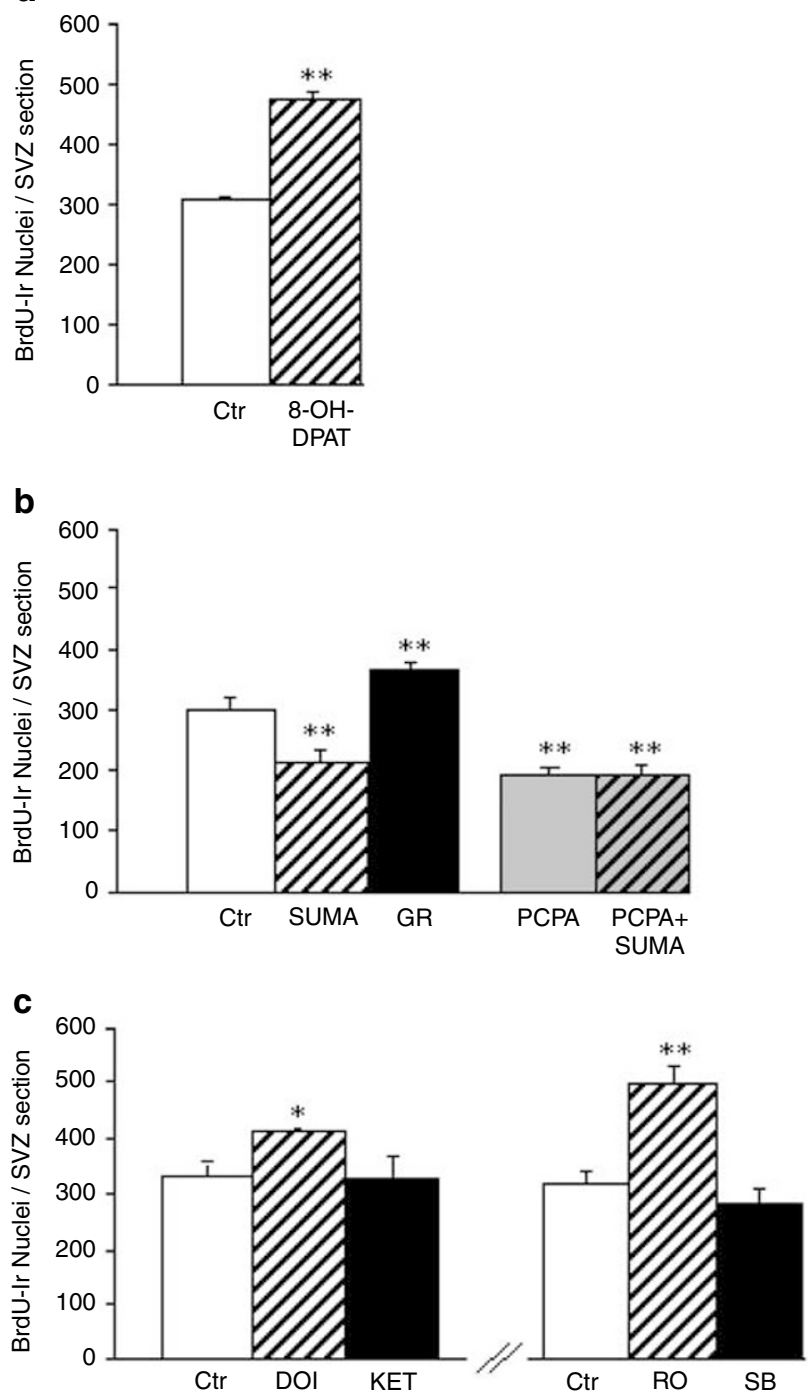

Figure 4 Effects of serotonergic treatments on the number of BrdUlabeled cells in the subventricular zone. (a) As compared to control, a large increase in the number of proliferative cells is observed in 8-OH-DPATtreated rats (4h). (b) Increases in the number of BrdU-labeled cells are observed in GR 127935-treated rats compared to controls and changes are opposite following sumatriptan administration. Furthermore, sumatriptan has no effect in PCPA-treated rats. (c) A small but significant increase in cell proliferation is observed in DOI-treated rats, which is larger after selective 5-HT2C receptor agonist administration RO. Both 5-HT2A/2C and 5$\mathrm{HT} 2 \mathrm{C}$ receptor antagonists are ineffective in modulating the level of cell proliferation. Data are presented as numbers of BrdU-labeled cells per section (means $\pm S E M$ ) from five or six rats per group. $* p<0.05$, $* * p<0.0$ I compared to controls (Ctr).

transmission may have a key role in regulating adult neurogenesis in the DG.

Using both selective and nonselective 5 -HT2C receptor agonists, we were unable to detect changes in the number of BrdU nuclei in the SGL. No changes in neurogenesis were observed after acute or chronic administration. The lack of effect of 5-HT2C receptor antagonists strengthens the view that this receptor subtype is not involved in the regulation of DG cell proliferation, in contrast with 5-HT2A receptors.
The ketanserin-induced decreases in the number of BrdUpositive cells can be related to a blockade of 5-HT2A receptors since this drug has a much higher selectivity for 5-HT2A than 5-HT2C receptor subtypes. Such a decrease might result from a disinhibition of granule cell activity via the blockade of 5-HT2A receptor expressed by the GABAergic inhibitory interneurons (Morilak et al, 1994). Apparently, these interpretations are in contrast with recent findings indicating that $5-\mathrm{HT} 2 \mathrm{C}$ receptors are expressed in neurospheres derived from the adult hippocampus (Benninghoff et al, 2002a); but the expression of 5-HT2C receptors at the membrane of progenitors can depend on in vivo regulations.

Although we have not tested markers of cell proliferation other than BrdU, changes produced by the drugs we used are not resulting from changes in bioavailability of BrdU, by the fact that most often, these compounds give different results in the DG and the SVZ. Furthermore, changes in cell proliferation can hardly be related to drug-induced changes in behavior. Indeed, most of the treated rats do not exhibit noticeable behavioral changes, except for PCPA-treated rats showing increases in motor activity and decreases in cell proliferation, whereas exercise increases hippocampal cell proliferation.

\section{Regulation of Cell Proliferation and Neurogenesis in the SVZ and OB}

The present study demonstrates for the first time that 5-HT, throughout 5-HT1A receptors, is a potent factor of stimulation of cell proliferation in the SVZ and consequently on neurogenesis in $\mathrm{OB}$. This result is in line with our previous data showing significant decreases in cell proliferation in SVZ after acute or chronic 5-HT depletion (Brezun and Daszuta, 1999). Indeed, the profuse network of 5-HT fibers in the walls of the cerebral ventricles has long been described in the mammalian brain (Lorez and Richards, 1982) and using paracrine mode of transmission, 5-HT can reach various cell populations in the surroundings, notably the neural stem cells or progenitors. As in the hippocampus, this observation suggests that the site of 5-HT action should be local, and 5-HT1A possibly located on progenitors and/or astrocytes can participate in this regulation.

The decreases and increases in the number of BrdU nuclei observed in the SVZ following the administration of 5-HT1B agonist and antagonist, respectively, underscore the fact that regulating extracellular levels of 5-HT throughout terminal 5-HT1B autoreceptors can modulate cell proliferation in this region. Indeed, the administration of the 5-HT1B receptors agonist has no effect in PCPA-pretreated rats.

In contrast to the DG, large increases in cell proliferation were observed in the SVZ following administration of the selective 5-HT2C agonist; such changes were reproduced to a smaller extent by the 5-HT2A/2C agonist. Increases in neurogenesis in $\mathrm{OB}$ were also observed after acute or chronic stimulation of 5-HT2C receptors. Indeed, diffuse 5HT transmission can readily activate 5-HT2C receptors expressed by the choroid plexus (Clemett et al, 2000) that can release FGF2 (Cuevas et al, 1994), a factor known to increase adult neurogenesis (Kuhn et al, 1997; Palmer et al, 
Dentate gyrus

a

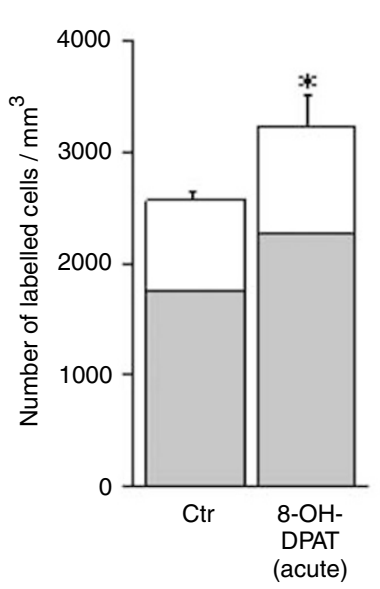

c

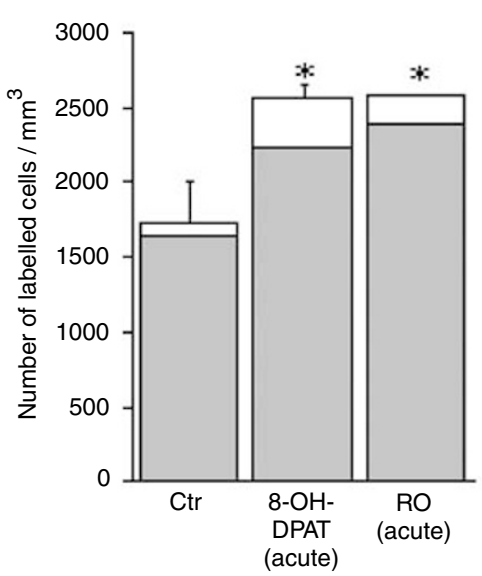

b

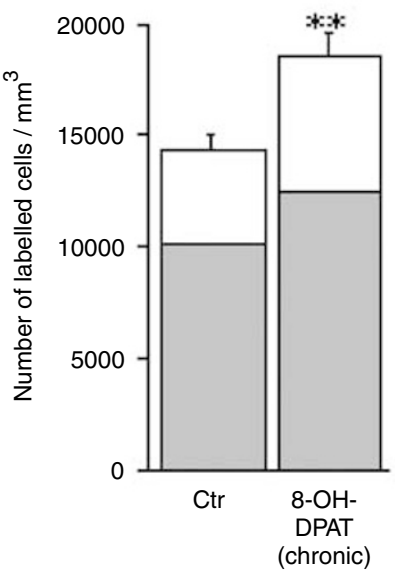

Olfactory bulb

d

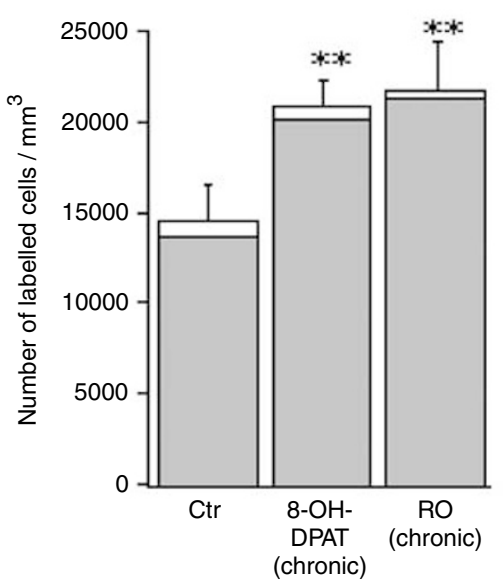

Figure 5 Effects of acute or chronic (I5 days) administrations of 5-HTIA or 5-HT2C receptor agonists on neurogenesis in the DG and OB. Effects of acute administrations of 5-HT receptor agonists were measured after a double injection of BrdU the same day, while BrdU was injected twice a day for the last 8 days of chronic treatments with 5-HT drugs. Significant increases in the number of newborn neurons detected 4 weeks following BrdU injections are observed after either acute or chronic administrations of each compound in both regions examined. The bars show the number of BrdU cells per mm ${ }^{3}$ of either GCL of the DG or GCL of OB. The colored portions of the bars depict the subpopulation of cells, which was also labeled with the neuron-specific marker NeuN, as determined by confocal microscopy. Data shown are means \pm SEM ( $n=6$ per group) $* p<0.05$, *** $p<0.01$ compared to controls (Ctr).

1999). Furthermore, the lack of change observed in 5-HT2C receptor antagonist-treated rats suggests a phasic serotonergic stimulation of cell proliferation in the SVZ via 5HT2C receptors.

\section{5-HT Receptors, Depression, and Neurogenesis}

Pharmacological studies in rodent models as well as clinical trials have indicated that 5-HT1A receptor agonists have antidepressant effects (De Vry, 1995; Martin et al, 1990). The present study demonstrates that chronic activation of 5-HT1A receptors produces significant increases in DG and $\mathrm{OB}$ neurogenesis, and even an acute administration of 8-OH-DPAT can stimulate the formation of new neurons in these regions. Additionally, the increase in cell proliferation observed in the dorsal hippocampus after the administration of 8-OH-DPAT, can be extended to the entire hippocampus as indicated by the present study of neurogenesis. These results are consistent with preliminary data showing that anxiolytic properties of chronic activation of 5-HT1A receptors by $8-\mathrm{OH}-\mathrm{DPAT}$ are associated with significant increases in DG cell proliferation, and that fluoxetine-induced increases in hippocampal neurogenesis are dependent on 5-HT1A receptor activation (Santarelli et al, 2003). In line with these data, we show here that the activation of 5-HT1A receptors produces significant increases in neurogenesis not only in the DG but also in the $\mathrm{OB}$, as a consequence of the increases in cell proliferation observed in the SVZ. Such results might be the support of the way by which SSRIs contribute, via activation of 5-HT1A, to morphological adaptations in various brain regions, particularly the hippocampus and the cortex.

The activation of terminal 5-HT1B autoreceptors can limit the increase in extracellular 5-HT produced by SSRIs 
in various regions (Malagie et al, 2001, Moret and Briley, 2000) and regulate 5-HT-induced changes in cell proliferation. However, it has also been indicated that the activation of 5-HT1B heteroreceptors mediates the antidepressant-like effects of SSRIs (Gardier et al, 2001). These data can be related to the positive changes in hippocampal cell proliferation observed in the present study following activation of 5-HT1B receptors in PCPA treated rats.

Finally, the 5-HT2 receptors can also play a role in depression and anxiety (Middlemiss et al, 2002). The decrease in cell proliferation detected in the hippocampus following acute 5-HT2A receptor blockade is difficult to associate with antidepressant effects of 5-HT2A receptor antagonists, but has to be confirmed by more selective 5HT2A pharmacology. In contrast, the increases observed in cell proliferation in the SVZ, or neurogenesis in the OB, following administration of selective 5-HT2C receptor agonist are consistent with the increases in 5-HT2C binding in choroid plexus induced by fluoxetine (Laakso et al, 1996), and the therapeutic potential of 5-HT2C receptor agonists (Martin et al, 1998). However, it remains to explain why fluoxetine has no effect on cell proliferation in the SVZ (Malberg et al, 2000).

\section{CONCLUSION}

The results obtained in the present study demonstrate that different 5-HT receptor subtypes can be positively involved in the stimulation of cell proliferation and neurogenesis in the adult brain induced by activation of 5-HT transmission. The consistent 5-HT1A-induced stimulation of neurogenesis in the two neurogenic zones and the selective implication of 5-HT2C receptors in the SVZ, and consequently the $\mathrm{OB}$, suggest that various neural circuits participate in the regulation of adult neurogenesis. Furthermore, long-term effects of chronic administration of 5HT1A or 5-HT2C receptor agonists on adult neurogenesis sustain the hypothesis of a relationship between the formation of new neurons and depression treatments. In view of the low level of cell proliferation in the normal mature brain, exposure to pharmacological compounds selective of 5-HT receptors and able to increase the production of new neurons can potentiate the use of neural precursors for brain repair.

\section{ACKNOWLEDGEMENTS}

This research was supported by the Association pour la Recherche sur le Cancer (ARC) as a fellowship to M Banasr. Part of this work was presented at the Third Forum of European Neuroscience (Paris, France, 2002). RO 600175 was a generous gift from Hoffmann-La Roche.

\section{REFERENCES}

Aberg MA, Aberg ND, Hedbacker H, Oscarsson J, Eriksson PS (2000). Peripheral infusion of IGF-I selectively induces neurogenesis in the adult rat hippocampus. J Neurosci 20: 2896-2903. Alvarez-Buylla A, Seri B, Doetsch F (2002). Identification of neural stem cells in the adult vertebrate brain. Brain Res Bull 57: $751-758$.
Banasr M, Hery M, Brezun JM, Daszuta A (2001). Serotonin mediates oestrogen stimulation of cell proliferation in the adult dentate gyrus. Eur J Neurosci 14: 1417-1424.

Barnes NM, Sharp T (1999). A review of central 5-HT receptors and their function. Neuropharmacology 38: 1083-1152.

Benninghoff J, Mössner R, Kreutzer A, Mûller-Botz U, Schlösser R, Schmitt A et al (2002a). Evidence for serotonergic (5-HT) impact on generation of neural stem cells derived from hippocampus of adult mice. Eur Soc Neurosci Abstr 038: 5.

Benninghoff J, Schmitt A, Mossner R, Lesch KP (2002b). When cells become depressed: focus on neural stem cells in novel treatment strategies against depression. J Neural Transm 109: 947-962.

Brezun JM, Daszuta A (1999). Depletion in serotonin decreases neurogenesis in the dentate gyrus and the subventricular zone of adult rats. Neuroscience 89: 999-1002.

Brezun JM, Daszuta A (2000a). Serotonergic reinnervation reverses lesion-induced decreases in PSA-NCAM labeling and proliferation of hippocampal cells in adult rats. Hippocampus 10: 37-46.

Brezun JM, Daszuta A (2000b). Serotonin may stimulate granule cell proliferation in the adult hippocampus, as observed in rats grafted with foetal raphe neurons. Eur J Neurosci 12: 391-396.

Cameron HA, McEwen BS, Gould E (1995). Regulation of adult neurogenesis by excitatory input and NMDA receptor activation in the dentate gyrus. $J$ Neurosci 15: 4687-4692.

Clemett DA, Punhani T, Duxon MS, Blackburn TP, Fone KC (2000). Immunohistochemical localisation of the 5-HT2C receptor protein in the rat CNS. Neuropharmacology 39: 123-132.

Compan V, Dusticier N, Nieoullon A, Daszuta A (1996). Opposite changes in striatal neuropeptide $\mathrm{Y}$ immunoreactivity after partial and complete serotonergic depletion in the rat. Synapse 24: 87-96.

Cuevas P, Carceller F, Reimers D, Fu X, Gimenez-Gallego G (1994). Immunohistochemical localization of basic fibroblast growth factor in choroid plexus of the rat. Neurol Res 16: 310-312.

Dekeyne A, Girardon S, Millan MJ (1999). Discriminative stimulus properties of the novel serotonin (5-HT) $2 \mathrm{C}$ receptor agonist, $\mathrm{RO}$ 60-0175: a pharmacological analysis. Neuropharmacology 38: 415-423.

De Vry J (1995). 5-HT1A receptor agonists: recent developments and controversial issues. Psychopharmacology (Berl) 121: 1-26.

Duman RS, Malberg J, Nakagawa S (2001). Regulation of adult neurogenesis by psychotropic drugs and stress. J Pharmacol Exp Ther 299: 401-407.

Fuchs E, Gould E (2000). Mini-review: in vivo neurogenesis in the adult brain: regulation and functional implications. Eur $J$ Neurosci 12: 2211-2214.

Gage FH (2000). Mammalian neural stem cells. Science 287: 14331438.

Gardier AM, Trillat AC, Malagie I, David D, Hascoet M, Colombel MC et al (2001). 5-HT1B serotonin receptors and antidepressant effects of selective serotonin reuptake inhibitors. C R Acad Sci III 324: 433-441.

Gould E, McEwen BS, Tanapat P, Galea LA, Fuchs E (1997). Neurogenesis in the dentate gyrus of the adult tree shrew is regulated by psychosocial stress and NMDA receptor activation. J Neurosci 17: 2492-2498.

Gould E, Tanapat P, Hastings NB, Shors TJ (1999). Neurogenesis in adulthood: a possible role in learning. Trends Cogn Sci 3: 186-192.

Gundersen HJ, Bagger P, Bendtsen TF, Evans SM, Korbo L, Marcussen $\mathrm{N}$ et al (1988). The new stereological tools: disector, fractionator, nucleator and point sampled intercepts and their use in pathological research and diagnosis. APMIS 96: 857-881.

Jacobs BL, van Praag H, Gage FH (2000). Adult brain neurogenesis and psychiatry: a novel theory of depression. Mol Psychiatry 5: 262-269. 
Kempermann G (2002). Regulation of adult hippocampal neurogenesis - implications for novel theories of major depression. Bipolar Disord 4: 17-33.

Kempermann G, Kuhn HG, Gage FH (1997). More hippocampal neurons in adult mice living in an enriched environment. Nature 386: 493-495.

Kennett GA, Wood MD, Bright F, Cilia J, Piper DC, Gager T et al (1996). In vitro and in vivo profile of SB 206553, a potent 5-HT2C/5-HT2B receptor antagonist with anxiolytic-like properties. Br J Pharmacol 117: 427-434.

Kokaia Z, Lindvall O (2003). Neurogenesis after ischaemic brain insults. Curr Opin Neurobiol 13: 127-132.

Kuhn HG, Winkler J, Kempermann G, Thal LJ, Gage FH (1997). Epidermal growth factor and fibroblast growth factor-2 have different effects on neural progenitors in the adult rat brain. J Neurosci 17: 5820-5829.

Kulkarni VA, Jha S, Vaidya VA (2002). Depletion of norepinephrine decreases the proliferation, but does not influence the survival and differentiation, of granule cell progenitors in the adult rat hippocampus. Eur J Neurosci 16: 20082012.

Laakso A, Palvimaki EP, Kuoppamaki M, Syvalahti E, Hietala J (1996). Chronic citalopram and fluoxetine treatments upregulate $5-\mathrm{HT} 2 \mathrm{c}$ receptors in the rat choroid plexus. Neuropsychopharmacology 15: 143-151.

Lee HJ, Kim JW, Yim SV, Kim MJ, Kim SA, Kim YJ et al (2001). Fluoxetine enhances cell proliferation and prevents apoptosis in dentate gyrus of maternally separated rats. Mol Psychiatry 6: 610 725-728.

Lorez HP, Richards JG (1982). Supra-ependymal serotoninergic nerves in mammalian brain: morphological, pharmacological and functional studies. Brain Res Bull 9: 727-741.

Malagie I, Trillat AC, Bourin M, Jacquot C, Hen R, Gardier AM (2001). 5-HT1B Autoreceptors limit the effects of selective serotonin re-uptake inhibitors in mouse hippocampus and frontal cortex. J Neurochem 76: 865-871.

Malberg JE, Eisch AJ, Nestler EJ, Duman RS (2000). Chronic antidepressant treatment increases neurogenesis in adult rat hippocampus. J Neurosci 20: 9104-9110.

Manev R, Uz T, Manev H (2001a). Fluoxetine increases the content of neurotrophic protein S100beta in the rat hippocampus. Eur $J$ Pharmacol 420: R1-R2.

Manev H, Uz T, Smalheiser NR, Manev R (2001b). Antidepressants alter cell proliferation in the adult brain in vivo and in neural cultures in vitro. Eur J Pharmacol 411: 67-70.

Martin JR, Bos M, Jenck F, Moreau J, Mutel V, Sleight AJ et al (1998). 5-HT2C receptor agonists: pharmacological characteristics and therapeutic potential. J Pharmacol Exp Ther 286: 913-924.

Martin P, Beninger RJ, Hamon M, Puech AJ (1990). Antidepressant-like action of 8-OH-DPAT, a 5-HT1A agonist, in the learned helplessness paradigm: evidence for a postsynaptic mechanism. Behav Brain Res 38: 135-144.

Maura G, Marcoli M, Tortarolo M, Andrioli GC, Raiteri M (1998). Glutamate release in human cerebral cortex and its modulation by 5-hydroxytryptamine acting at $h$ 5-HT1D receptors. Br J Pharmacol 123: 45-50.

Middlemiss DN, Price GW, Watson JM (2002). Serotonergic targets in depression. Curr Opin Pharmacol 2: 18-22.

Mitsikostas DD, Papadopoulou-Daifotis Z, Sfikakis A, Varonos D (1996). The effect of sumatriptan on brain monoamines in rats. Headache 36: 29-31.
Moret C, Briley M (2000). The possible role of 5-HT(1B/D) receptors in psychiatric disorders and their potential as a target for therapy. Eur J Pharmacol 404: 1-12.

Morilak DA, Somogyi P, Lujan-Miras R, Ciaranello RD (1994). Neurons expressing 5-HT2 receptors in the rat brain: neurochemical identification of cell types by immunocytochemistry. Neuropsychopharmacology 11: 157-166.

Nacher J, Rosell DR, Alonso-Llosa G, McEwen BS (2001). NMDA receptor antagonist treatment induces a long-lasting increase in the number of proliferating cells, PSA-NCAM-immunoreactive granule neurons and radial glia in the adult rat dentate gyrus. Eur J Neurosci 13: 512-520.

Owens MJ, Edwards E, Nemeroff CB (1990). Effects of 5-HT1A receptor agonists on hypothalamo-pituitary-adrenal axis activity and corticotropin-releasing factor containing neurons in the rat brain. Eur J Pharmacol 190: 113-122.

Palmer TD, Markakis EA, Willhoite AR, Safar F, Gage FH (1999). Fibroblast growth factor-2 activates a latent neurogenic program in neural stem cells from diverse regions of the adult CNS. J Neurosci 19: 8487-8497.

Parent JM (2002). The role of seizure-induced neurogenesis in epileptogenesis and brain repair. Epilepsy Res 50: 179-189.

Pellegrino L (1979). A Stereotaxic Atlas for the Rat Brain. Plenum Press: New York.

Piguet P, Galvan M (1994). Transient and long-lasting actions of 5 -HT on rat dentate gyrus neurones in vitro. J Physiol 481(Part 3): 629-639.

Radley JJ, Jacobs BL (2002). 5-HT1A receptor antagonist administration decreases cell proliferation in dentate gyrus. Brain Res 955: 264-267.

Riad M, Garcia S, Watkins KC, Jodoin N, Doucet E, Langlois X et al (2000). Somatodendritic localization of 5-HT1A and preterminal axonal localization of 5-HT1B serotonin receptors in adult rat brain. J Comp Neurol 417: 181-194.

Rochefort C, Gheusi G, Vincent JD, Lledo PM (2002). Enriched odor exposure increases the number of newborn neurons in the adult olfactory bulb and improves odor memory. J Neurosci 22: 2679-2689.

Santarelli L, Saxe M, Gross C, Surget A, Battaglia F, Dulawa S et al (2003). Requirement of hippocampal neurogenesis for the behavioral effects of antidepressants. Science 301: 805-809.

Semont A, Fache M, Hery F, Faudon M, Youssouf F, Hery M (2000). Regulation of central corticosteroid receptors following short-term activation of serotonin transmission by 5-hydroxy-Ltryptophan or fluoxetine. J Neuroendocrinol 12: 736-744.

Shingo T, Gregg C, Enwere E, Fujikawa H, Hassam R, Geary C et al (2003). Pregnancy-stimulated neurogenesis in the adult female forebrain mediated by prolactin. Science 299: 117-120.

Skingle M, Beattie DT, Scopes DI, Starkey SJ, Connor HE, Feniuk W et al (1996). GR127935: a potent and selective 5-HT1D receptor antagonist. Behav Brain Res 73: 157-161.

Taupin P, Gage FH (2002). Adult neurogenesis and neural stem cells of the central nervous system in mammals. J Neurosci Res 69: 745-749.

Vaidya VA, Marek GJ, Aghajanian GK, Duman RS (1997). 5-HT2A receptor-mediated regulation of brain-derived neurotrophic factor mRNA in the hippocampus and the neocortex. J Neurosci 17: 2785-2795.

Whitaker-Azmitia PM, Clarke C, Azmitia EC (1993). Localization of 5-HT1A receptors to astroglial cells in adult rats: implications for neuronal-glial interactions and psychoactive drug mechanism of action. Synapse 14: 201-205. 